\title{
Approximate periodic solutions to MEMS oscillator subject to magnetostatic excitation
}

\author{
Ji-huan He ${ }^{1}$, Piotr Sebastian Skrzypacz ${ }^{2}$, Yanni Zhang ${ }^{3}$, and Jing Pang ${ }^{3}$ \\ ${ }^{1}$ Soochow University \\ ${ }^{2}$ Nazarbayev University \\ ${ }^{3}$ Inner Mongolia University of Technology
}

July 4, 2020

\begin{abstract}
A way to obtain approximate periodic solutions to nonlinear oscillators arising in a micro-electro-mechanical system (MEMS) is presented for the case of zero initial conditions and magnetostatic excitation. The frequency-amplitude relationship is derived by adopting He's frequency formulation. The obtained analytical results are illustrated graphically. The proposed simple approach gives the fast insight into the dynamics of the singular oscillator and can be useful for design of MEMS devices.
\end{abstract}

\section{Hosted file}

mems-1_v2_(1) (1).docx available at https://authorea.com/users/299696/articles/465947approximate-periodic-solutions-to-mems-oscillator-subject-to-magnetostatic-excitation 


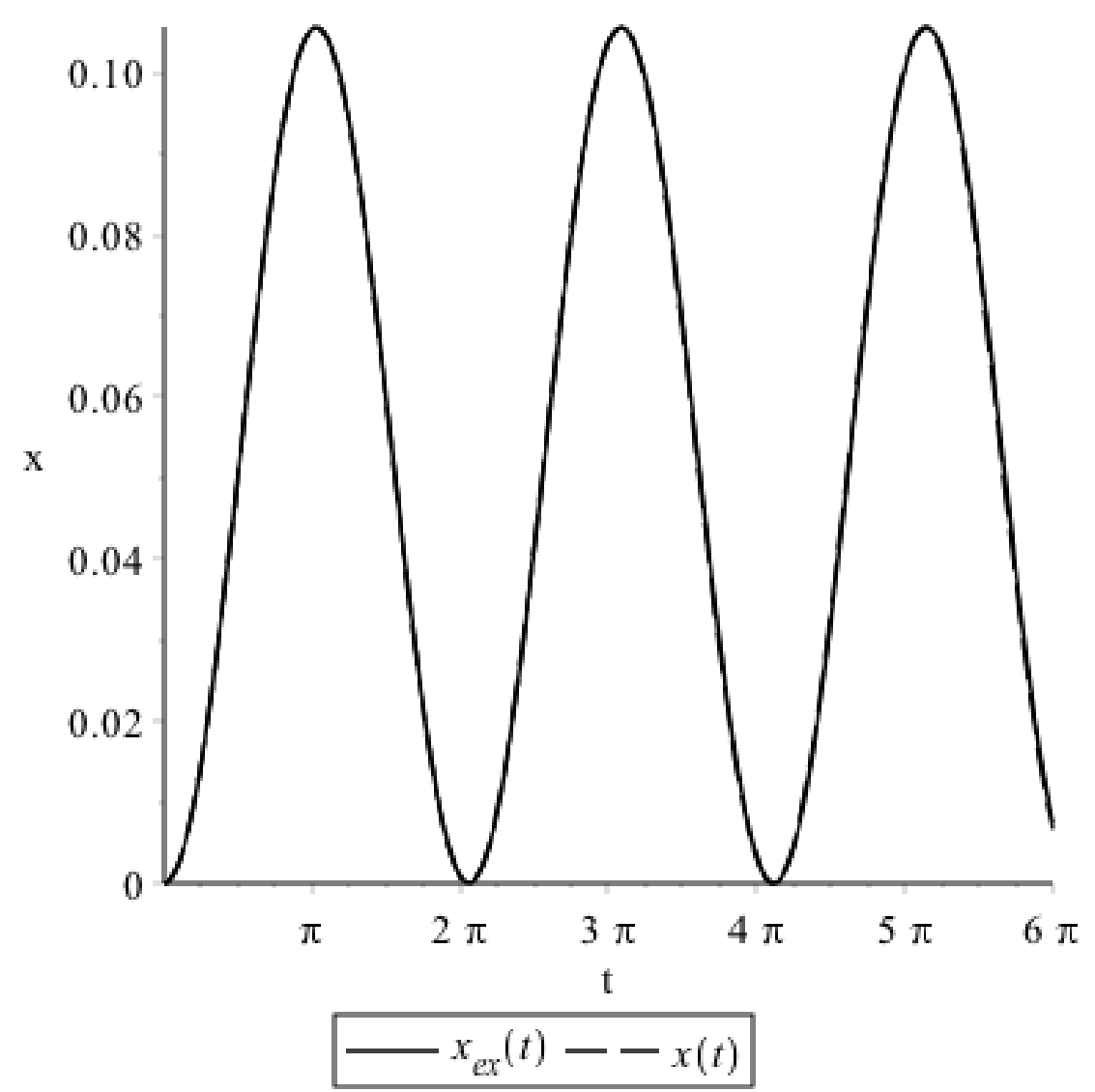




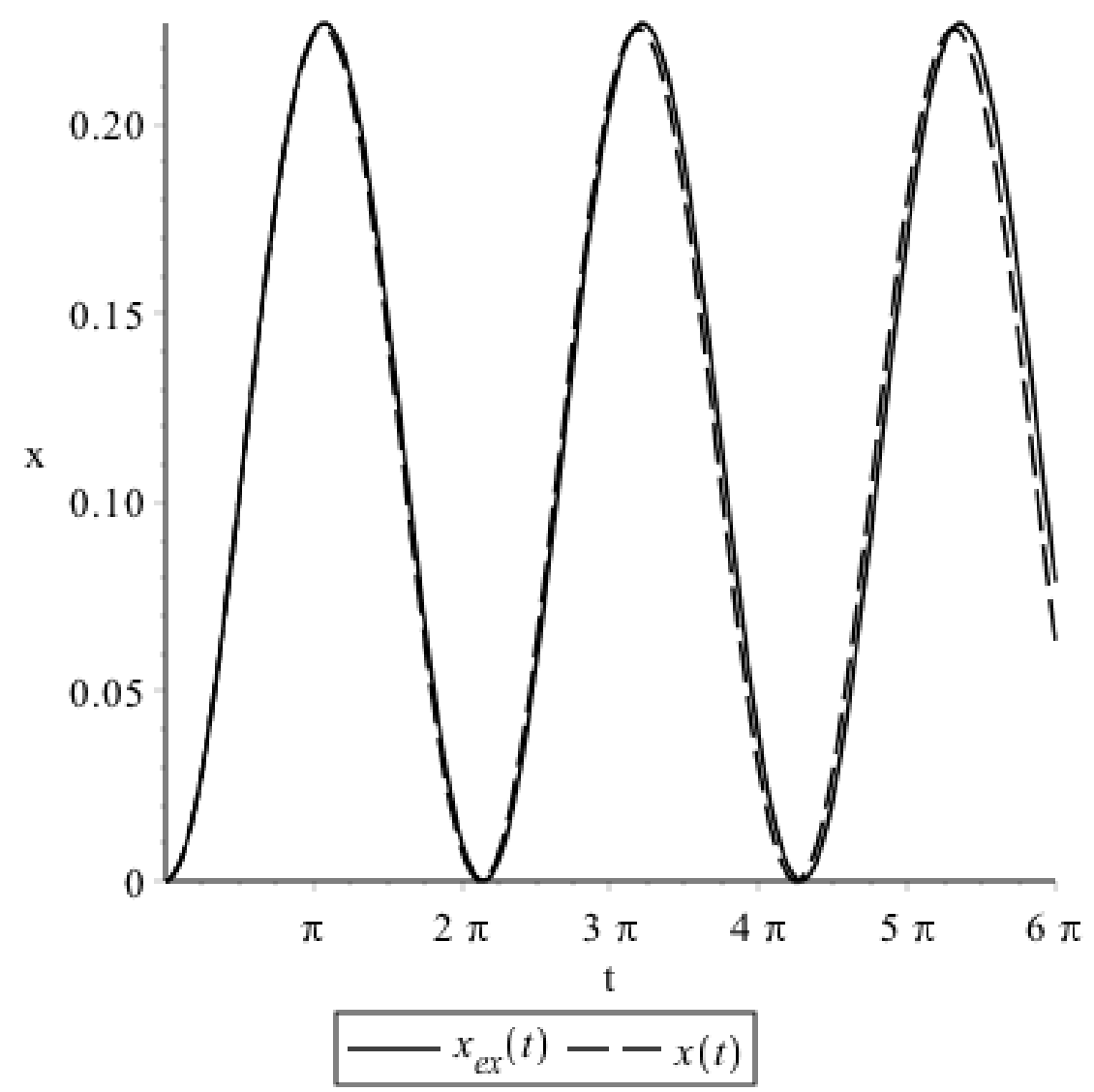




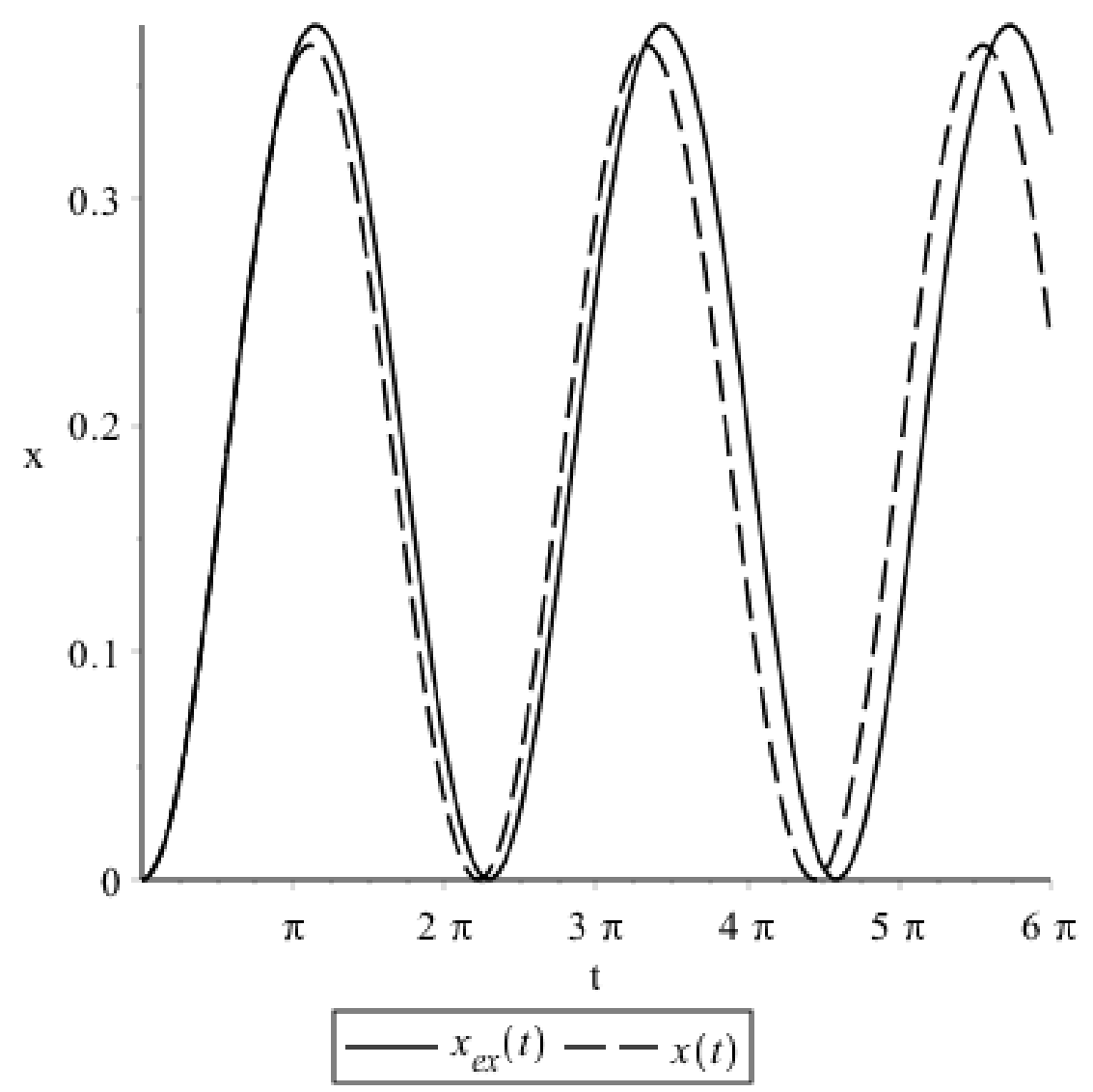




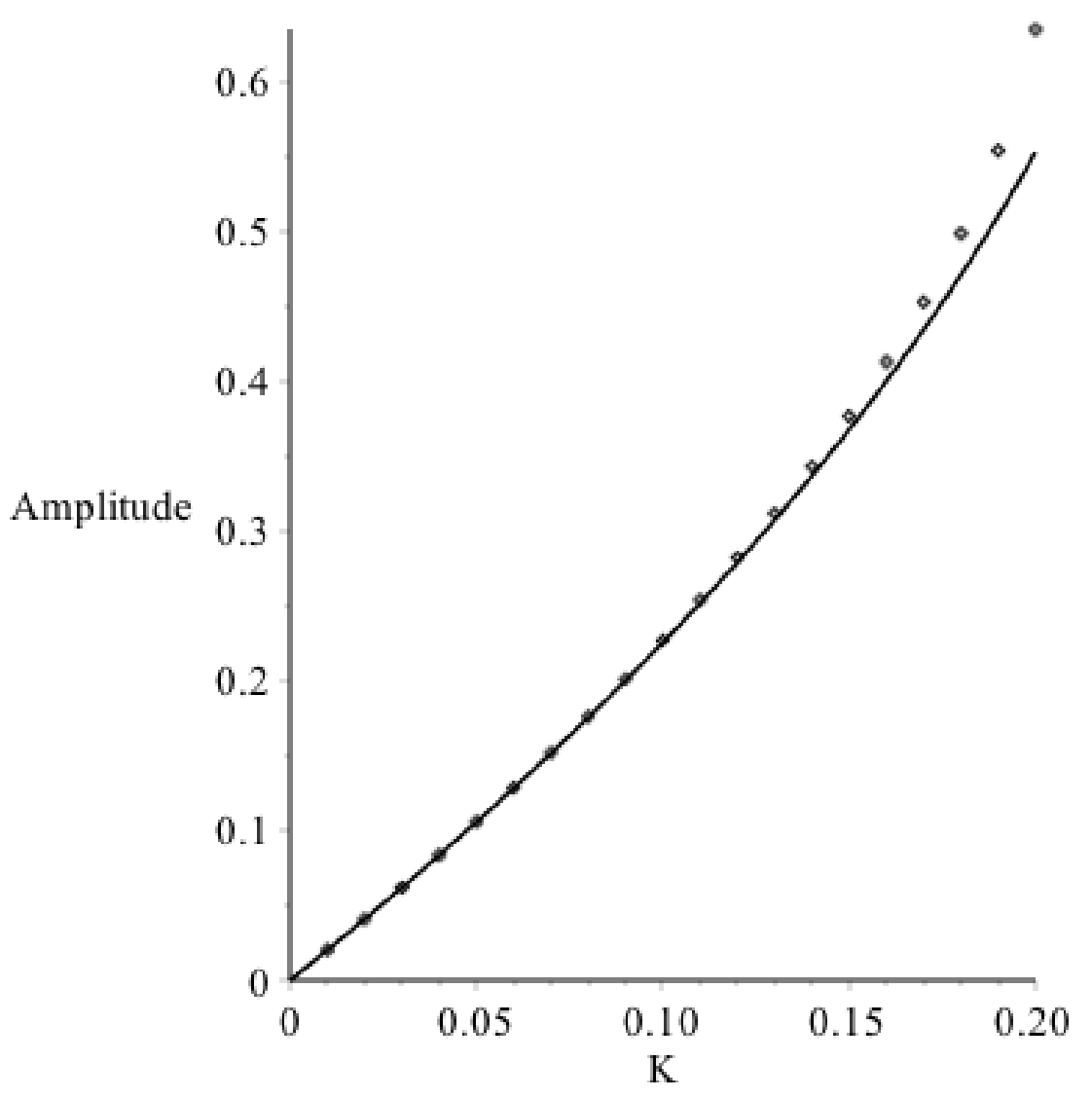




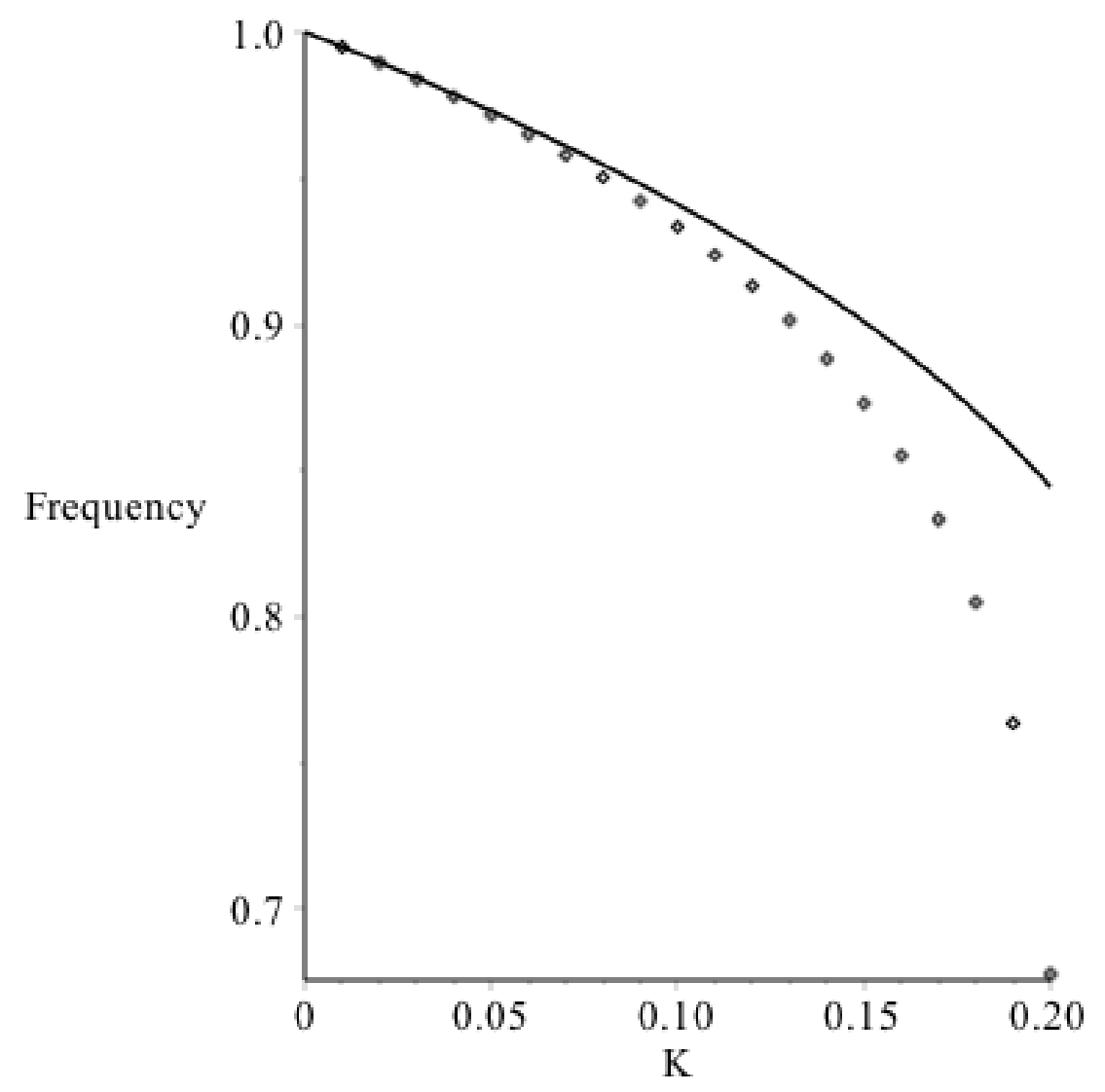

